\title{
A METHOD OF PARAMETRIC MODELING IN FORENSIC LINGUISTICS ${ }^{1}$
}

\author{
Pavel A. Katyshev \\ Pushkin State Russian Language Institute, Moscow, Russia \\ Mikhail A. Osadchiy \\ Pushkin State Russian Language Institute, Moscow, Russia
}

\begin{abstract}
The paper contains a substantiation of the method of parametric modeling used in forensic linguistics. An expert analysis procedure is described as an algorithm for evaluating texts using a closed list of parameters by standard formulas. Parametrization is the modeling of a process or phenomenon includes such items as features of a phenomenon (process), normative (prototypical) forms of each of the phenomenon features (process) manifestation, manifestation variation range which does not destroy phenomenon (process) identity. Legal risk parametrization in communication is carried out by building a parametric forensic-linguistic model of the offense. This model consists of the following components: the parameter code, parameters' list for identifying verbal offense signs, each parameter identifying verbal offense signs qualitative manifestations, each parameter identifying verbal offense signs quantitative manifestations, each parameter identifying offense verbal signs qualification indices, all identification parameters offense verbal signs indices qualification sum. A parametric model is developed on the appeal speech act example; it allows building an expert analysis algorithm that can be checked and reproduced. According to this model, we can observe the presense or the lack of linguistic offense signs under Art. 280 of the Russian Federation Criminal Code (public appeal for extremist activity). In the analysis of the call for one and verbal manifestations of extremism, a classification of calls based on the characteristics relevant to forensic linguistic expertise is proposed.
\end{abstract}

Key words: forensic linguistics, forensic linguistic expertise, parameterization, speech act of appeal, extremism.

Citation. Katyshev P. A., Osadchiy M.A. A Method of Parametric Modeling in Forensic Linguistics. Vestnik Volgogradskogo gosudarstvennogo universiteta. Seriya 2, Yazykoznanie [Science Journal of Volgograd State University. Linguistics], 2018, vol. 17, no. 3, pp. 24-34. (in Russian). DOI: https://doi.org/10.15688/jvolsu2.2018.3.3

\section{МЕТОД ПАРАМЕТРИЧЕСКОГО МОДЕЛИРОВАНИЯ В СУДЕБНОЙ ЛИНГВИСТИКЕ ${ }^{1}$}

\author{
Павел Алексеевич Катышев \\ Государственный институт русского языка им. А.С. Пушкина, г. Москва, Россия \\ Михаил Андреевич Осадчий \\ Государственный институт русского языка им. А.С. Пушкина, г. Москва, Россия
}

Аннотация. Статья содержит обоснование метода параметрического моделирования, который применяется при проведении судебной лингвистической экспертизы. Процедура экспертного анализа описана как алгоритм оценки текстов по закрытому перечню параметров в соответствии со стандартными формулами. Параметризация представляет собой моделирование процесса или явления, при котором выполняется установление состава признаков явления (процесса), нормативных (прототипических) форм проявления каждого из признаков явления (процесса), диапазона варьирования форм проявления каждого из признаков, не раз- 
рушающего идентичности явления (процесса). Параметризация правового риска в коммуникации выполняется путем построения параметрической судебно-лингвистической модели правонарушения. На примере речевого акта призыва разработана параметрическая модель, позволяющая строить проверяемый и воспроизводимый алгоритм экспертного анализа и делать вывод о наличии либо отсутствии лингвистических признаков правонарушения, которое предусмотрено ст. 280 УК РФ (публичный призыв к экстремистской деятельности). В ходе анализа призыва как одного из вербальных проявлений экстремизма предложена классификация призывов, основанная на признаках, релевантных для судебной лингвистической экспертизы: наличием в высказывании образа адресата, образа способа совершения действия, образа объекта действия, вербального императива.

Ключевые слова: судебная лингвистика, судебная лингвистическая экспертиза, параметризация, призыв, экстремизм.

Цитирование. Катышев П. А., Осадчий М. А. Метод параметрического моделирования в судебной лингвистике // Вестник Волгоградского государственного университета. Серия 2, Языкознание. - 2018. - Т. 17, № 3. - C. 24-34. - DOI: https://doi.org/10.15688/jvolsu2.2018.3.3

\section{Введение}

Статья основана на исследованиях, проведенных ранее (см., например: [Осадчий, 2014]) и требующих переосмысления в свете существенно изменившейся экспертной практики последних пяти лет.

Правовая квалификация перформативна, представляет собой прямое действие, последствия которого носят неотвратимый и системный характер. По этой причине она стремится к идеалу точной, алгоритмизированной процедуры, ведущей к однозначным выводам. Любая неоднозначность и вариативность, свойственная объективным явлениям и процессам, преодолевается понятийными и процедурными конвенциями, вырабатываемыми правоприменительным и экспертным сообществами.

Все это в полной мере относится и к речевой коммуникации как сфере правоотношений. Корректное применение к коммуникации правовых оценок требует, прежде всего, операционализации субъективных исследовательских понятий [Леонтьев, 2009] и параметризации коммуникативного процесса. Последняя позволяет описать состав признаков явлений и процессов, прототипические формы проявления признаков и диапазон их варьирования; операционализация дает возможность упорядочить, алгоритмизировать оценку явлений и процессов с опорой на список заданных параметров и их значений.

Метод параметризации, зародившийся в сфере инженерии и точных вычислений, давно и успешно используется в лингвистичес- ком моделировании [Демьянков, 1996]. Важным этапом развития параметрического моделирования в лингвистике стали работы, в которых принцип параметризации был выведен за пределы имманентной модели и применен к описанию деятельностного аспекта языка - процессам усвоения языка и патологии речи [Bates, Bretherton, Snyder, 1988; Flynn, O’Neil, 1988; Gleitman et al., 1988]. В последние годы элементы параметрического моделирования широко используются отечественными лингвистами в исследованиях по семантике [Заикина, 2012], теории дискурса [Булатова, 2011; Комалова, 2010; Назаров, 2012 и др.], психологии коммуникации [Долотин, 2008].

\section{Принципы}

\section{параметрического моделирования в судебной лингвистике}

В общенаучном смысле параметризация представляет собой моделирование процесса или явления, при котором выполняются три действия:

- установление состава признаков явления (процесса);

- установление нормативных (прототипических) форм проявления каждого из признаков явления (процесса);

- установление диапазона варьирования форм проявления каждого из признаков, не разрушающего идентичности явления (процесса).

Таким образом, в качестве параметра можно рассматривать любой конститутивный 
признак явления (процесса), описанный в динамике его качественного и количественного проявления в заданном диапазоне [Лопатников, 2003; Моисеев, 2006 и др.].

Параметризация правового риска в коммуникации выполняется путем построения параметрической судебно-лингвистической модели правонарушения. В данную модель закладываются следующие компоненты:

1) код параметра;

2) список параметров идентификации вербальных признаков правонарушения;

3) качественные проявления каждого параметра идентификации вербальных признаков правонарушения;

4) количественные проявления каждого параметра идентификации вербальных признаков правонарушения;

5) квалификационные показатели каждого параметра идентификации вербальных признаков правонарушения;

6) квалификационная сумма показателей всех параметров идентификации вербальных признаков правонарушения.

Параметрическая модель имеет вид таблицы (см. ниже), в которой перечисленные выше компоненты заложены в столбцах с первого по пятый. Квалификационная сумма показателей всех параметров вычисляется в нижней строке, там же описывается квалифи- кационная формула вычисления получившейся суммы.

Из приведенной таблицы видно, что каждый параметр может иметь одно или несколько качеств проявления. Например, в случае с оскорблением параметр неприличности может выражаться обсценными словами (качество 1), грубыми ругательствами (качество 2) или эвфемизмами и табуированными образами (качество 3). Количественная характеристика степени проявления каждого из качеств выполняется в системе двоичного исчисления от 0 до 1 , где 0 означает непроявленность качества (например, если в высказывании нет обсценных слов), а 1 - проявление качества (напротив, если в тексте есть обсценные слова). В столбце «Квалификационный количественный показатель параметра» указывается суммарное значение параметра, необходимое для того, чтобы усматривать в тексте признаки правонарушения. Например, если проявление какого-либо параметра характеризует три качества, а квалификационная сумма показателей параметра задана в диапазоне от 1 до 3 [1; 3], это означает, что для идентификации по данному параметру признака преступления необходимо, чтобы параметр проявился на уровне хотя бы одного из характеризующих его качеств; если же квалификационная сумма показателей параметра зада-

Общий вид параметрической судебно-лингвистической модели

\begin{tabular}{|c|c|c|c|c|}
\hline $\begin{array}{c}\text { Код } \\
\text { пара- } \\
\text { метра }\end{array}$ & $\begin{array}{c}\text { Наименование } \\
\text { параметра }\end{array}$ & $\begin{array}{c}\text { Качественные } \\
\text { характеристики } \\
\text { реализации } \\
\text { параметра }\end{array}$ & $\begin{array}{c}\text { Количественные } \\
\text { характеристики } \\
\text { реализации } \\
\text { параметра }\end{array}$ & $\begin{array}{c}\text { Квалификационный } \\
\text { количественный } \\
\text { показатель } \\
\text { параметра (группы } \\
\text { параметров) }\end{array}$ \\
\hline \multicolumn{5}{|c|}{ Параметры группы А } \\
\hline \multirow[t]{2}{*}{$\mathbf{A 1}$} & \multirow[t]{2}{*}{ Параметр 1} & Качество 1 & {$[0 ; 1]$} & \multirow{2}{*}{$\Sigma 1$} \\
\hline & & Качество 2 & {$[0 ; 1]$} & \\
\hline $\mathbf{A 2}$ & Параметр 2 & Качество 1 & {$[0 ; 1]$} & $\Sigma 0$ \\
\hline \multicolumn{5}{|c|}{ Параметры группы В } \\
\hline \multirow[t]{5}{*}{ B1 } & \multirow[t]{5}{*}{ Параметр 3} & Качество 1 & {$[0 ; 1]$} & \multirow{5}{*}{$\Sigma[1 ; 5]$} \\
\hline & & Качество 2 & {$[0 ; 1]$} & \\
\hline & & Качество 3 & {$[0 ; 1]$} & \\
\hline & & Качество 4 & {$[0 ; 1]$} & \\
\hline & & Качество 5 & {$[0 ; 1]$} & \\
\hline \multirow[t]{4}{*}{ B2 } & \multirow[t]{4}{*}{ Параметр 4} & Качество 1 & {$[0 ; 1]$} & \multirow{4}{*}{$\Sigma[1 ; 4]$} \\
\hline & & Качество 2 & {$[0 ; 1]$} & \\
\hline & & Качество 3 & {$[0 ; 1]$} & \\
\hline & & Качество 4 & {$[0 ; 1]$} & \\
\hline
\end{tabular}


на в значении 0, это означает, что для идентификации признака преступления необходимо полное отсутствие проявлений по данному параметру. Например, для идентификации сведений порочащего характера необходимо, чтобы модальная рамка гипотетичности не проявилась ни в какой из форм (в тексте точно не должно быть слов мне кажется, по моему мнению и т. д.).

Нижняя строка «Квалификационная сумма показателей параметров» содержит данные о сумме «баллов», которую нужно «набрать», чтобы с уверенностью констатировать наличие вербальных признаков правонарушения. При этом важна не просто сумма «баллов», а то, на каких именно параметрах данные «баллы» набираются, то есть квалификационная формула. Например, признаки правонарушения $X$ усматриваются по двум параметрам - Параметру А и Параметру В, квалификационная сумма равна 1 , при квалификационной формуле 'при $A=1, B=0$ '. Если итоговая сумма 1 будет набрана по другой формуле - 'при $A=0, B=1$ ', то вербальные признаки правонарушения не усматриваются.

\section{Структурная и семантическая параметризация призыва}

В ходе расследования публичных призывов к осуществлению экстремистской деятельности правоприменитель сталкивается с трудностями понятийного и методологического характера, о чем неоднократно говорилось в специальной литературе [Баранов, 2007, c. 412-476; Бринев, 2010; Воронцов, 2007; Голев, 2007; Кукушкина, Сафонова, Секераж, 2011, с. 87-96; Осадчий, 2014 и др.].

С когнитивной точки зрения успешный призыв формирует в сознании адресата речи картину действия, к которому осуществлен призыв, то есть образ базового фрейма SPO (субъект - действие - объект). Важнейшим условием успешности призыва как коммуникативного события является согласие адресата речи с ролью $\mathrm{S}$ (исполнителя действия, к которому осуществлен призыв) при заполненности слотов Р и О (ясном осознании способа совершения действия и объекта действия).

Вербальная составляющая успешного призыва в наиболее общем виде характе- ризуется следующими лингвистическими признаками:

1) наличием в высказывании образа адpecama (A);

2) наличием в высказывании образа сnособа совершения действия (Д);

3) наличием в высказывании образа объекта действия $(\mathrm{O})$;

4) наличием в высказывании вербального императива (И).

Образ адресата в успешном призыве всегда равен адресату речи - декларированному или фактическому. При несовпадении образа адресата призыва и фактического адресата (или при отказе фактического адресата соотносить себя с образом адресата призыва) коммуникативный акт становится неуспешным. При этом на уровне локуции образ адресата призыва может характеризоваться как нулевой, так и максимальной конкретностью. Примером призывов, содержащих образ адресата с убывающей степенью конкретности, может служить следующий ряд: Русский, решай!; Гражданин, защищаий свои права!; Скажи власти свое «нет»!; Bnеред, на баррикадыл! В отличие от образа способа совершения действия и образа объекта действия образ адресата не имеет какихлибо квалификационных признаков в терминах ст. 1 Ф3 «О противодействии экстремистской деятельности» и ст. 280 УК РФ. Степень конкретности образа адресата призыва, безусловно, имеет влияние на меру успешности призыва, но не изменяет квалификацию в терминах закона.

Образ способа совершения действия может иметь широкий диапазон конкретности - от нулевой до максимальной. Первый из них имеет место при призывных конструкциях, содержащих «чистое» побуждение. Например: Русский, решайся! Давай же, вперед! В приведенном высказывании вербальный императив сочетается с семантической неконкретностью (нулевой конкретностью). В этом случае успешность призыва оказывается под вопросом, поскольку высказывание не содержит оснований для заполнения слотов базового фрейма SPO. Даже при внутреннем согласии адресата речи с самоидентификацией ' $Я$ = S' (да, я тот самый русский, к которому обращаются) отсутствие вербальных ос- 
нований для заполнения слотов $\mathrm{P}$ и О делает призыв неуспешным (Что же именно делать, на что решаться?). В такой ситуации большую роль может сыграть контекст: при наличии невербальных стимулов, детерминирующих ассоциативную деятельность адресата (изображений, фоновых событий), фрейм SPO может дополниться, повышая успешность призыва.

Максимальная конкретность образа способа совершения действия достигается при использовании глаголов с конкретным значением (Выгнать их с рынка!; Не пускайте их на избирательные участки, там место только русским). Конкретизация призыва может происходить аналитическим путем, когда побудительная и конкретно-лексическая семантика реализуются в разных частях высказывания или в разных высказываниях, связанных на грамматическом и / или ассоциативно-композиционном уровне (Русский, действуй! Настало время посадить всех инородиев на поезда до гранииы!).

В судебной лингвистике степень конкретности образа способа совершения действия, по всей видимости, должна измеряться не только семиотически - по уровню абстракции семантики лексемы, обозначающей данный способ совершения действия, но и квалификационно - по достаточности / недостаточности оснований для идентификации квалифицирующего способа совершения действия, интерпретируемого в терминах ст. 1 Ф3 «О противодействии экстремистской деятельности» и ст. 280 УК РФ (насильственные действия, действия, ограничивающие права и законные интересы объекта, действия по подготовке и совершению теракта и т. п.).

Образ объекта действия, как и образ способа совершения действия, может иметь разную степень проявления - от нулевой до максимальной. Нулевая степень проявления образа объекта действия может усматриваться в призывных высказываниях типа Русский, решай! Все на борьбу!, в которых нулевой образ объекта действия совпадает с лексическим нулем, то есть с отсутствием в высказывании лексического репрезентанта предмета / существа / явления как мишеней наводимого действия. При этом нулевой образ объекта действия имеет место и при наличии в высказывании лексического репрезентанта объекта действия - лексемы с абстрактной семантикой в условиях минимального контекста. Ярким примером такого рода призыва является плакатное высказывание, получившее распространение в блогосфере рунета Долби систему! Примером призыва, содержащего конкретный образ объекта действия может служить высказывание Очистим страну от иновериев!

По аналогии со способом совершения действия в ходе судебно-лингвистического анализа степень конкретности образа объекта действия, по всей видимости, должна измеряться не только семиотически, но и квалификационно - по достаточности / недостаточности оснований для идентификации квалифицирующего объекта, интерпретируемого в терминах ст. 1 Ф3 «О противодействии экстремистской деятельности» и ст. 280 УК РФ (национальной, расовой, социальной групп или их представителей; атрибутов конституционного строя, специфических объектов террористической деятельности и т. п.).

Вербальный императив является элементом речи с побудительным значением. Он может быть выражен императивной формой глагола (Уничтожь!) или семантически эквивалентными формами:

- инклюзивным волитивом (Поборемся! Избавим! Дадим отпор!);

- формами прошедшего времени в составе восклицательных высказываний (Поили! Встали!);

- формами инфинитива в составе восклицательных высказываний (Взять! Bставать!);

- формами инфинитива в сочетании с частицами давай, пусть (Давай бороться! Пусть грянет револючия!);

- неглагольными формами со значением побуждения в составе восклицательных высказываний (В бой! Вперед! Огонь! Смерть врагам!).

Наработанная экспертная практика позволяет утверждать, что в реальной коммуникации призывные высказывания не всегда соответствуют предложенной четырехкомпонентной модели призыва. Она может реализоваться как полно, так и частично. Возможна следующая парадигма вариантов реализации модели призыва: 
1) $\underline{\mathbf{A}}-\underline{\boldsymbol{Z}}-\underline{\mathbf{O}}-\underline{\mathbf{U}}$ (сильный полный призыв);

2) А - Д- $\underline{\mathbf{0}}-\underline{\mathbf{Z}}$ (сильный действеннообъектный призыв);

3) А - Д - $\underline{\mathbf{o}}-\underline{\boldsymbol{U}}$ (слабый объектный призыв);

4) $\mathrm{A}-\underline{\Xi}-\mathrm{O}-\underline{\mathbf{Z}}$ (слабый действенный призыв);

5) $\underline{\mathbf{A}}-$ Д - О - $\underline{\mathbf{U}}$ (слабый адресатный призыв);

6) $\underline{\mathbf{A}}-$ Д - $\underline{\mathbf{O}}-\underline{\mathbf{U}}$ (слабый адресатнообъектный призыв);

7) $\underline{\mathbf{A}}-\underline{\boldsymbol{Z}}-\mathrm{O}-\underline{\boldsymbol{U}}$ (слабый адресатнодейственный призыв).

Необходимо сразу уточнить, что термин «сильный» применительно к призыву употребляется в специальном судебно-лингвистическом смысле как указатель на возможность однозначной квалификации призыва в терминах закона (ст. 1 Ф3 «О противодействии экстремистской деятельности» и ст. 280 УК РФ).

Итак, сильным является полный призыв, в котором эксплицитно реализованы все четыре компонента: вербальный императив, образ объекта действия, образ способа совершения действия и образ адресата. Дальнейшие варианты реализации модели предполагают «выпадение» одного или нескольких компонентов схемы, что отдаляет высказывание от эталонного (с точки зрения правоприменителя) призыва. При этом необходимо сделать две оговорки. Во-первых, предложенная модель не допускает «выпадения» вербального императива (И), поскольку без данного компонента высказывание не может быть доказательно квалифицировано как призыв (случаям косвенных и скрытых призывов оценка будет дана ниже). Во-вторых, невыраженность образа адресата не снижает силу призыва, поскольку его адресованность не коррелирует с каким-либо квалификационным признаком призыва, закрепленным в диспозиции ст. 280 УК РФ, то есть данный компонент в принципе не является значимым параметром при правовой квалификации события призыва. Следовательно, призывное высказывание, соответствующее схеме с невыраженным адресатом, по правилам предложенной модели будет относиться к разряду сильных призывов.

Выделение двух структурных типов призыва - сильного и слабого - может быть сопоставлено с различением определенных и неопределенных призывов в: [Бринев, 2010, c. 182]. Важность такого различения следует из сути следственного процесса, частью которого является судебная лингвистическая экспертиза. Следствие направлено на установление в распространенном тексте не призывов в общем смысле, а конкретного вида призывов так называемых «экстремистских».

Вариативность в способах выражения императивности приводит к изменению квалификации высказывания как в лингвистическом, так и в юридическом аспектах. Такая вариативность может заключаться в замене вербального императива на мягкое воление, выраженное вопросом-рекомендацией (He стоит ли начать борьбу?), утверждением необходимости действий (Необходимо собраться на митинг у здания администраuии) или обоснованием действий, выраженным как развернутой аргументацией, так и простым указанием на правильность или своевременность неких действий (Настал час прекратить этот беспредел; Единственный выход для нас сейчас - заблокировать избирательный участок). С лингвистической точки зрения такие акты мягкого воления обладают признаками эксплицитного вербального побуждения к действиям, то есть призыва или побуждения - в широком смысле.

Вместе с тем нельзя отрицать и того, что мягкое воление принципиально отличается от вербального императива как на формальносемантическом, так и на прагматическом уровнях. С формально-семантической точки зрения высказывания, выражающие мягкое воление, отличаются от призывов отсутствием системных императивов - лексических, грамматических или структурных компонентов, регулярно выражающих побудительное значение. Так, императивные формы глагола (разрушь), глагольные формы будущего времени с инклюзивным значением (вытесним), инфинитив (встать), неглагольные элементы со значением приказа в составе восклицательных высказываний (подъем, в бой, огонь) выражают побуждение в пределах конкретного (русского) языка регулярно, то есть являются системными императивами. В то же время этикетные вопросы-рекомендации, обоснование или утверждение необходимости дей- 
ствий эксплицируют побуждение ситуативно. С прагматической точки зрения в высказываниях, выражающих мягкое воление, побуждение реализуется как одна из интенций говорящего, не обязательно даже основная. При этом в сильных призывах побуждение является главной интенцией.

Все эти соображения позволяют заключить, что высказывания, содержащие вербальный императив, и высказывания, выражающие мягкое воление, хотя и являются императивными, волеизъявительными в широком смысле, но должны быть четко отделены друг от друга как принципиально разные типы призыва. Кроме того, в первом случае можно говорить о прямом призыве, во втором - о косвенном призыве.

Итак, косвенный призыв является вариантом реализации модели призыва, при котором вербальный императив (компонент И) остается неэксплицированным и заменяется на одну из форм мягкого воления. При этом косвенный призыв в общем виде все же реализуется по модели призыва. Высказывание с косвенным призывом может содержать в большей или меньшей степени эксплицированный образ объекта действия, образ способа совершения действия и образ адресата. Исходя из этого, можно выстроить парадигму вариантов реализации модели косвенного призыва, подобную той, что была предложена выше для призыва:

1) $\underline{\mathbf{A}}-\boldsymbol{\Xi}-\underline{\mathbf{O}}-$ И (адресный действеннообъектный сильный косвенный призыв): в высказывании эксплицированы образ объекта действия, образ способа совершения действия и образ адресата (Товарищ, настало время выкинуть эту власть из кабинетов!);

2) А - Д- $\underline{\mathbf{0}}-$ И (безадресный действенно-объектный сильный косвенный призыв): в высказывании эксплицированы образ способа совершения действия и образ объекта действия (Самый верный шаг - депортировать всех черных);

3) $\underline{\mathbf{A}}-\underline{Д}-\mathrm{O}$ - И (адресно-действенный слабый косвенный призыв): в высказывании эксплицированы образ адресата и образ способа совершения действия (Русский, тебе нужно драться за свою землю!);

4) $\underline{\mathbf{A}}-$ Д - О - И (адресный слабый косвенный призыв): в высказывании эксплициро- ван только образ адресата (Всем горожанам нужно начать активно и организованно сопротивляться);

5) $\underline{\mathbf{A}}-$ Д - $\underline{\mathbf{0}}-$ И (адресно-объектный слабый косвенный призыв): в высказывании эксплицированы образ адресата и образ объекта действия (Однопартийцы, да неужели ж мы не справимся с этой воровской властью?).

Как и в случае с прямым призывом, термин «сильный» применительно к косвенному призыву употребляется в специальном судебно-лингвистическом смысле как указатель на возможность однозначной квалификации призыва в терминах закона. При этом очевидно, что ни один из вариантов реализации косвенного призыва не дает нам высказывания, которое могло бы быть квалифицировано как призыв в терминах ст. 280 УК РФ. Однако косвенные призывы могут быть квалифицированы в терминах ст. 282 УК РФ (возбуждение ненависти и вражды). Эти призывы в дальнейшем будут именоваться слабыми.

Таким образом, при всем типологическом различии прямой и косвенный призывы демонстрируют схожесть как по структуре высказывания, так и по структуре парадигмы варьирования. Прямой и косвенный призывы совокупно могут быть противопоставлены призыву, который отличается не способом реализации модели А-Д-О-И, а самой моделью образования.

В судебной практике часто приходится сталкиваться с текстами, в которых деятельные стимулы реализуются исключительно на уровне подтекста и могут быть распознаны адресатом только интуитивно. Иными словами, тексты не содержат ни прямых, ни косвенных призывов, но при восприятии текста интуиция адресата распознает некие стимулы. Тексты такого типа содержат информацию, подталкивающую, подстрекающую к каким-либо действиям, направленно формирующую у адресата желание действовать или чувство необходимости действий. Такие тексты нередко дают развернутую программу действий, к которым подстрекают, то есть автор программирует поведение адресата речи, нередко используя методы речевой манипуляции сознанием, воздействия на психи- 
ку, подсознание читателя или слушателя. Такого рода случаи являются примерами реализации скрытого призыва и противопоставляются открытому призыву - прямому и косвенному.

Скрытый призыв является той проблемной зоной, в которой обостряется методологический конфликт между правоприменителем и экспертом-лингвистом. С точки зрения права скрытый призыв не может быть однозначно квалифицирован в терминах ст. 1 Ф3 «О противодействии экстремистской деятельности», ст. 280 УК РФ (публичные призывы к осуществлению экстремистской деятельности) или ст. 282 УК РФ (возбуждение ненависти и вражды), поскольку побудительный компонент речи в таких случаях не выделяется, не объективируется в конкретных лексемах или конструктах, которым можно было бы придать статус признака преступления. При этом лингвистический взгляд на скрытый призыв принципиально иной: наукой накоплено достаточно фактов, свидетельствующих в пользу того, что скрытый призыв обладает даже большим побудительным потенциалом, нежели открытый. Открытый призыв является в некотором смысле «честным» способом воздействия на поведение адресата речи, так как он открыт и быстро себя обнаруживает в глазах читателя или слушателя. Законопослушный адресат речи понимает, что на него оказывается воздействие, потому он может вовремя принять меры по обеспечению собственной информационной безопасности (чаще такими мерами становится простой уход от контакта). В случае со скрытым призывом реакция по противодействию запаздывает и адресат становится более уязвимым.

С процедурной точки зрения квалифицированным как «призыв к экстремистской деятельности» может быть только открытый прямой сильный призыв, поскольку он обладает объективированными, проверяемыми признаками призыва. Установление призыва в данном случае не требует применения узкоспециальных технологий, неклассических научных методов, по результатам использования которых могут быть получены выводы, не отвечающие принципу проверяемости и воспроизводимости.

\section{Выводы}

В параметрическую модель целесообразно закладывать характеристики открытого прямого сильного призыва. При этом параметр силы является сложным, он может быть разложен на параметр образа совершения действия и параметр образа объекта. Параметры открытости и прямоты являются в большей степени структурными, поскольку в их аспекте принципиальное значение для квалификации призыва имеет простое наличие конкретных структурных элементов в конфликтном высказывании (наличие в конфликтном тексте высказывания, построенного по схеме призыва, и наличие в данном высказывании вербального императива). В то же время такой параметр, как сила, разложенный на два более простых параметра - образа совершения действия и образа объекта, - является в большей степени семантическим, поскольку в аспекте данного параметра ключевым моментом выступает содержание структурных элементов призывного высказывания.

Призыв к совершению экстремистской деятельности - это высказывание (группа смежных высказываний), отвечающее следующим признакам в их совокупности:

- в высказывании реализована полная или сокращенная схема призыва (А-Д-О-И);

- в высказывании реализован вербальный императив;

- вербальный императив побуждает к совершению действия (действий) одним или несколькими из перечисленных способов: путем насильственных действий; путем террористической деятельности; путем нарушения прав, свободы и законных интересов; путем воспрепятствования, соединенного с насилием либо угрозой его применения; путем совершения преступлений (в том числе убийства, причинения вреда здоровью, побоев, хулиганства, вандализма и т. д.); путем пропаганды и публичного демонстрирования; путем организации, подготовки, подстрекательства; путем финансирования либо иного содействия в организации, подготовке и осуществлении, в том числе путем предоставления учебной, полиграфической и материально-технической базы, телефонной и иных видов связи или оказания информационных услуг; 
- вербальный призыв побуждает к совершению действий в отношении одного или нескольких из перечисленных объектов: существующего конституционного строя; населения; человека и гражданина в зависимости от его социальной, расовой, национальной, религиозной или языковой принадлежности или отношения к религии; избирательных прав граждан, права на участие в референдуме или нарушения тайны голосования; законной деятельности государственных органов, органов местного самоуправления, избирательных комиссий, общественных и религиозных объединений или иных организаций; человека как представителя политической, идеологической, расовой, национальной, социальной группы / предмета как атрибута политической, идеологической, расовой, национальной, социальной группы; нацистской атрибутики или символики либо атрибутики или символики, сходных с нацистской атрибутикой или символикой до степени смешения.

Косвенные и скрытые призывы не соответствуют данной модели, поскольку нечетко квалифицируются как призывы в смысле ст. 280 УК РФ и тяготеют к полю возбуждения вражды в смысле ст. 282 УК РФ. В связи с этим дальнейшее рассмотрение алгоритма экспертной оценки вербальных проявлений экстремизма требует обсуждения вопросов, связанных с вариантами дифференциации признаков преступлений, предусмотренных ст. 282 УК РФ.

\section{ПРИМЕЧАНИЕ}

${ }^{1}$ Исследование выполнено в рамках гранта РФФИ № 17-29-09170 «Исследование психофизиологических и психолингвистических особенностей восприятия и декодирования поликодовых текстов экстремистской направленности».

\section{СПИСОК ЛИТЕРАТУРЫ}

Баранов А. Н., 2007. Лингвистическая экспертиза текста: теория и практика. М. : Флинта : Наука. 592 с.

Бринев К. И., 2010. Теоретическая лингвистика и судебная лингвистическая экспертиза : дис. ... д-ра филол. наук. Кемерово. 363 с.

Булатова Э. В., 2011. К вопросу о типологических и структурных параметрах дискурса // Известия
Уральского федерального университета. Серия 1. Проблемы образования, науки и культуры. № 2 (89). С. 111-116.

Воронцов С. А., 2007. Понятие экстремизма и его сущностные признаки // Философия права. № 4. C. 65-71.

Голев Н. Д., 2007 «...Восстать, вооружиться, победить...»: Шекспир и экстремизм // Юрислингвистика 8: Русский язык и современное российское право : межвуз. сб. науч. тр. / под ред. Н. Д. Голева. Барнаул : Изд-во Алт. ун-та. С. 412-416.

Демьянков В. 3., 1996. Параметризация // Краткий словарь когнитивных терминов. М. : Филологический факультет МГУ им. М.В. Ломоносова. С. 118-123.

Долотин К. И., 2008. Количественная оценка эмоционального напряжения говорящего по временным параметрам квазисегментной структуры речевого сигнала (психофизическое шкалирование) // Вопросы психолингвистики. № 8. С. 128-133.

Заикина О. Н., 2012. О параметрах комплексного анализа семантической категории (на примере концепта «Луна» в русском языке) // Человек. Культура. Образование. № 3 (5). С. 89-98.

Комалова Л. Р., 2010. Диагностика уровня конфликтности предконфликтной коммуникации (по просодическим параметрам) // Вестник Московского государственного лингвистического университета. № 592. С. 100-114.

Кукушкина О. В., Сафонова Ю. А., Секераж Т. Н., 2011. Теоретические и методологические основы судебной психолого-лингвистической экспертизы по делам, связанным с противодействием экстремизму. М. : РФЦСЭ. $326 \mathrm{c.}$

Леонтьев Д. А., 2009. К операционализации понятия «толерантность» // Вопросы психологии. №5. C. 3-16.

Лопатников Л. И., 2003. Экономико-математический словарь: словарь современной экономической науки. М. : Дело. 520 с.

Моисеев А. А., 2006. Автоматическая параметризация // Информационные технологии в проектировании и производстве. № 3. С. 85-88.

Назаров Н. В., 2012. К вопросу об универсальных параметрах описания речевых произведений // Вестник Центра международного образования Московского государственного университета. Филология. Культурология. Педагогика. Методика. №. 1. С. 33-38.

Осадчий М. А., 2014. Русский язык на грани права: Функционирование современного русского языка в условиях правовой регламентации речи. М. : Книжный дом «ЛИБРОКОМ». 256 с. 
Bates E., Bretherton I., Snyder L. S., 1988. From first words to grammar: Individual differences and dissociable mechanisms. Cambridge : Cambridge University Press. xii, $326 \mathrm{p}$.

Flynn S., O’Neil W., 1988. Introduction // Linguistic theory in second language acquisition. Dordrecht ; Boston ; London : Kluwer. P. 1-24.

Gleitman et al., 1988. Gleitman L. R., Gleitman H., Landau B., Wanner E. Where learning begins: Initial representations for language learning // Linguistic theory: Foundations. Cambridge : Cambridge University Press. P. 150-193.

\section{REFERENCES}

Baranov A.N., 2007. Linguistic expertise of the text: theory and practice. Moscow, Flinta; Nauka Publ. 592 p.

Brinev K.I., 2010. Theoretical linguistics and forensic linguistic expertise. Dr. philol. sci. diss. Kemerovo. 363 p.

Bulatova E.V., 2011. The Discourse types and the methods of the discourse analysis. Izvestiya Uralskogo federalnogo universiteta. Seriya 1. Problemyobrazovaniya, nauki i kultury, no. 2 (89), pp. 111-116.

Vorontsov S.A., 2007. The notion of extremism and its essential features. Filosofiya prava, no. 4, pp. 65-71.

Golev N.D., 2007. “...Rise up, arm, conquer...”: Shakespeare and extremism. Golev N.D., ed. Yurislingvistika 8: Russkiy yazyk i sovremennoe rossiyskoe pravo: mezhvuzovskiy sbornik nauchnykh trudov [Jurilinguistic-8: The Russian Language and Contemporary Russian Law]. Barnaul, Izd-vo Alt. un-ta, pp. 412-416.

Demyankov V.Z., 1996. Parameterization. Kratkiy slovar kognitivnykh terminov [A Brief Dictionary of Cognitive Terms]. Moscow, MGU Publ., pp. 118-123.

Dolotin K.I., 2008. Announcer's emotional state evaluation by means of quasisegmental structure of speech signal (psychophysical scaling). Voprosy psikholingvistiki [Journal of Psycholinguistics], no. 8, pp. 128-133.
Zaikina O.N., 2012. The parameters of complex analysis of semantic category (exemplified by the concept (moon'). Chelovek. Kultura. Obrazovanie [Human. Culture. Education], no. 3 (5), pp. 89-98.

Komalova L.R., 2010. Diagnosis of pre-conflict communication conflictivity (by prosodic parameters). Vestnik Moskovskogo gosudarstvennogo lingvisticheskogo universiteta [TheAcademic Research Journal MSLUVESTNIK. Linguistics], no. 592, pp. 100-114.

Kukushkina O.V., Safonova Yu.A., Sekerazh T.N., 2011. Theoretical and methodological basis of judicial psychological and linguistic expertise in cases related to countering extremism. Moscow, RFTsSE Publ. 326 p.

Leontyev D.A., 2009. Towards an operational definition of tolerance. Voprosy psikhologii, no. 5, pp. 3-16.

Lopatnikov L.I., 2003. Economic and mathematical dictionary: Dictionary of modern economics. Moscow, Delo Publ. 520 p.

Moiseev A.A., 2006. Automatic parameterization. Informatsionnye tekhnologii v proektirovanii i proizvodstve, no. 3, pp. 85-88.

Nazarov N.V., 2012. On the universal parameters describing the discourse. Vestnik Tsentra mezhdunarodnogo obrazovaniya Moskovskogo gosudarstvennogo universiteta. Filologiya. Kulturologiya. Pedagogika. Metodika, no. 1, pp. 33-38.

Osadchiy M.A., 2014. The Russian language on the verge of law: Functioning of the modern Russian language in terms of legal regulation of speech. Moscow, LIBROKOM Publ. 256 p.

Bates E., Bretherton I., Snyder L.S., 1988. From first words to grammar: Individual differences and dissociable mechanisms. Cambridge, Cambridge University Press. xii, $326 \mathrm{p}$.

Flynn S., O’Neil W., 1988. Introduction. Linguistic theory in second language acquisition. Dordrecht; Boston; London, Kluwer, pp. 1-24.

Gleitman L. R., Gleitman H., Landau B., Wanner E., 1988. Where learning begins: Initial representations for language learning. Linguistic theory: Foundations. Cambridge, Cambridge University Press, pp. 150-193. 


\section{Information about the Authors}

Pavel A. Katyshev, Doctor of Sciences (Philology), Professor of Department of General and Russian Linguistics, Pushkin State Russian Language Institute, Akademika Volgina St., 6, 117485 Moscow, Russia, pakatyshev@pushkin.institute, https://orcid.org/0000-0002-2492-6495

Mikhail A. Osadchiy, Doctor of Sciences (Philology), Professor of Department of General and Russian Linguistics, Vice-Rector for Science, Pushkin State Russian Language Institute, Akademika Volgina St., 6, 117485 Moscow, Russia, MAOsadchiy@pushkin.institute, https://orcid.org/0000-0001-7964-9029

\section{Информация об авторах}

Павел Алексеевич Катышев, доктор филологических наук, профессор кафедры общего и русского языкознания, Государственный институт русского языка им. А.С. Пушкина, ул. Академика Волгина, 6, 117485 г. Москва, Россия, pakatyshev@pushkin.institute, https://orcid.org/0000-00022492-6495

Михаил Андреевич Осадчий, доктор филологических наук, профессор кафедры общего и русского языкознания, проректор по науке, Государственный институт русского языка им. А.С. Пушкина, ул. Академика Волгина, 6, 117485 г. Москва, Россия, МАOsadchiy@pushkin.institute, https://orcid.org/ 0000-0001-7964-9029 